\title{
E-learning - from first experiences in medical physics and engineering to its role in times of crisis
}

\author{
Vassilka Tabakova ${ }^{1}$ \\ Received: 14 June 2020 / Accepted: 4 August 2020 / Published online: 22 August 2020 \\ (C) IUPESM and Springer-Verlag GmbH Germany, part of Springer Nature 2020
}

\begin{abstract}
The paper reviews briefly notable examples of e-learning, specifically the pioneering projects in medical physics and engineering. The needs for implementation of e-learning and the challenges to be resolved are underlined with a view of potential quick application of e-learning. The role of e-learning during times of crisis, such as the current COVID-19 pandemic is discussed and the need of adequate pre-preparedness is highlighted. Examples are shown from the recent book "e-Learning in Medical Physics and Engineering: Building Educational Modules with Moodle". Ways of reaching the target audience and the problems in some Lower-and-Middle Income countries are presented, together with some examples of quick adoption of e-Learning. The way forward has been argued, emphasizing that realistically the place of e-Learning is to complement traditional teaching and learning activities, enhancing their value and quality.
\end{abstract}

Keywords E-learning $\cdot$ eLearning $\cdot$ Medical physics education $\cdot$ Pioneering eLearning in medical physics

\section{Definition and types}

The term e-Learning evolved with the advance of the use of technology in education and it is argued that the pre-requisites for its appearance can be traced back to the 60-ies of the 20-th century and even before [1]. After this exact term was coined in the late 1990-ies, it came to encompass previously used terms such as "multimedia-based education" "computer-based training (CBT)", "electronic teaching materials". The term e-Learning gained popularity after the article "A Bright Future for Distance Learning" published in Nov 1997 by A. Morri [2].

It should be noted that there is not a single agreed definition of e-Learning. It is often stressed that e-Learning means different things in different sectors and nowadays it is generally accepted that in Higher Education, "e-Learning" refers to the use of both software-based and online learning. An important point to note is that e-Learning not only makes available documents in electronic format via online learning, but it encourages interaction between

This article is part of the Topical Collection on COVID-19 Health Technology: Design, Regulation, Management, Assessment

Vassilka Tabakova

assia.tabakova@emerald2.co.uk

1 Department of Medical Engineering and Physics, King's College London, London, UK the different users and develops a flexible paedagogical approach. A good source that explores the basic concepts as well as day-to-day issues of e-learning, looking both at theoretical concepts and practical implementation issues is the Guide on eLearning in Medical Education [3].

A variety of accompanying terms are in use in e-Learning related literature: the most frequently used being Virtual Learning Environment (VLE), Learning Management System (LMS), and also Managed Learning Environment (MLE), Learning Support System (LSS), etc. All these refer to online platforms and software systems configured to facilitate management and student involvement in e-Learning and describe a wide range of systems that organise and provide access to online education services for students, teachers, and administrators. These services usually include access control, provision of learning content, communication tools, and administration of user groups.

\section{The case for e-learning}

Today e-Learning is an intrinsic part of education and there is hardly need to make the case for its implementation. We shall list briefly here the three main features (enhanced quality of learning; facilitating its management and increased number of students) driving the development of e-Learning: 


\subsection{Enhanced quality of learning}

As discussed in a variety of papers e-Learning is moving more and more from representing an instruction paradigm to becoming a learning paradigm, where the teacher with a learning perspective provides student support and the students themselves actively discover and construct knowledge [4-6].

- Facilitating the management of learning is what makes the e-Learning platforms a welcome feature of contemporary education. The book "e-Learning in Medical Physics and Engineering: Building Educational Modules with Moodle" [7] illustrates this for Medical Physics and Medical Engineering, areas which make the case for the introduction of e-Learning a very strong one.

Pioneering educators in the field, such as the team behind the projects EMERALD, EMIT, EMITEL, [8] developed the first e-learning materials, including an educational image database, the first e-Dictionary and e-Encyclopaedia in medical physics and saw this potential of "computer-aided education" long before the term e-Learning was coined. The Project EMERALD (1995-1998), managed and coordinated by specialists from King's College London with partners from Universities and Hospitals in UK, Sweden, Italy, and Portugal developed the first educational databases in the profession on CD-ROM, which were one of the first digital publications in the world to be published with ISBN (in the way an ISBN is assigned to paper books). The concept of assigning an ISBN to e-material was also applied by other prestigious publishers and almost simultaneously (within 4 months) the world's first three such digital image databases were developed, EMERALD being one of them:

- Atlas of Pathology: Urological Pathology CD-ROM, Springer-Verlag, ISBN 3540146571, 30 December 1997,

- EMERALD Image Database, Training Courses in Medical Radiation Physics CD-ROM, King's College London, ISBN 1870722035, 19 February 1998,

- Developmental Psychology Image Database CD-ROM, McGraw-Hill, ISBN 0072896914, 30 April 1998,

\subsection{Increased number of students}

The evolution of e-Learning in Higher Education has witnessed examples when the driving force for the introduction of e-Learning has been economic efficiency alone, but sustainable examples show that it is a welcome achievement and logical consequence of many pioneering projects, without being a goal in itself.

The fact that the MSc programme in Medical Engineering and Physics (MEP) at King's College London, UK used elements of its own e-learning materials since 2002, and most lecturers followed a unified template for their handouts, facilitated smooth transition of the learning content to a specific VLE. Thus the number of students gradually increased from 38 part-time students in 2011 to 112 in 2013 with the same administrative resources. In this way the 3-year parttime MSc programme (split in sub-parts) became one of the largest courses in the profession in Europe.

This remarkable economic efficiency was achieved through implementing a pilot Moodle e-Learning platform in 2011 , managed by the author. The resulting enhanced quality of teaching and learning was reflected in the reviews of external assessors over the years. In yet another example the eLearning pack EMERALD, the first such pack to be developed in Medical Physics in 1996 was made available to about 50 students at the ICTP College on Medical Physics, Trieste, Italy and consequently the e-Learning pack was opened for access free of charge to all Medical Physicists from Low-andMiddle Income (LMI) countries, which led to a world-wide use of the e-materials (Fig.1 below).

In the concrete example of medical physics, e-Learning is a reliable tool to solve the necessity for almost tripling of medical physicists in the next 15 years especially in Low-and Middle Income countries. [7-9].

The pioneering projects of EMIT,EMITEL, EMERALD, and their global impact on a whole profession, have been contributing to this process since their launch. The contribution of their creators to education and e-Learning was recognised by the European Union when in December 2004 the EMIT Consortium was awarded the inaugural EU Award "Leonardo da Vinci" (Fig. 2). The author is one of the contributing Members to the award-winning EMIT Consortium [8].

What other problems does e-learning aim to solve:

There are a couple of important drivers for the increased use of e-Learning platforms in the wider community:

- the need to alleviate the shortage of teachers in specific subjects.

- the necessity to reach students at risk of dropping out of school or performing poorly.

- reaching dispersed population in countries like Canada or Australia or anywhere where it is not economical to build schools or post teachers.

As pointed by Twinomugisha in [10] all these problems are endemic in low-income countries across Africa.

\section{The challenges in front of e-learning. Prerequisites for its implementation}

The implementation of e-Learning has met some criticism for the failure to solve problems such as low engagement, low discipline, high drop-out (respectively low retention) student 


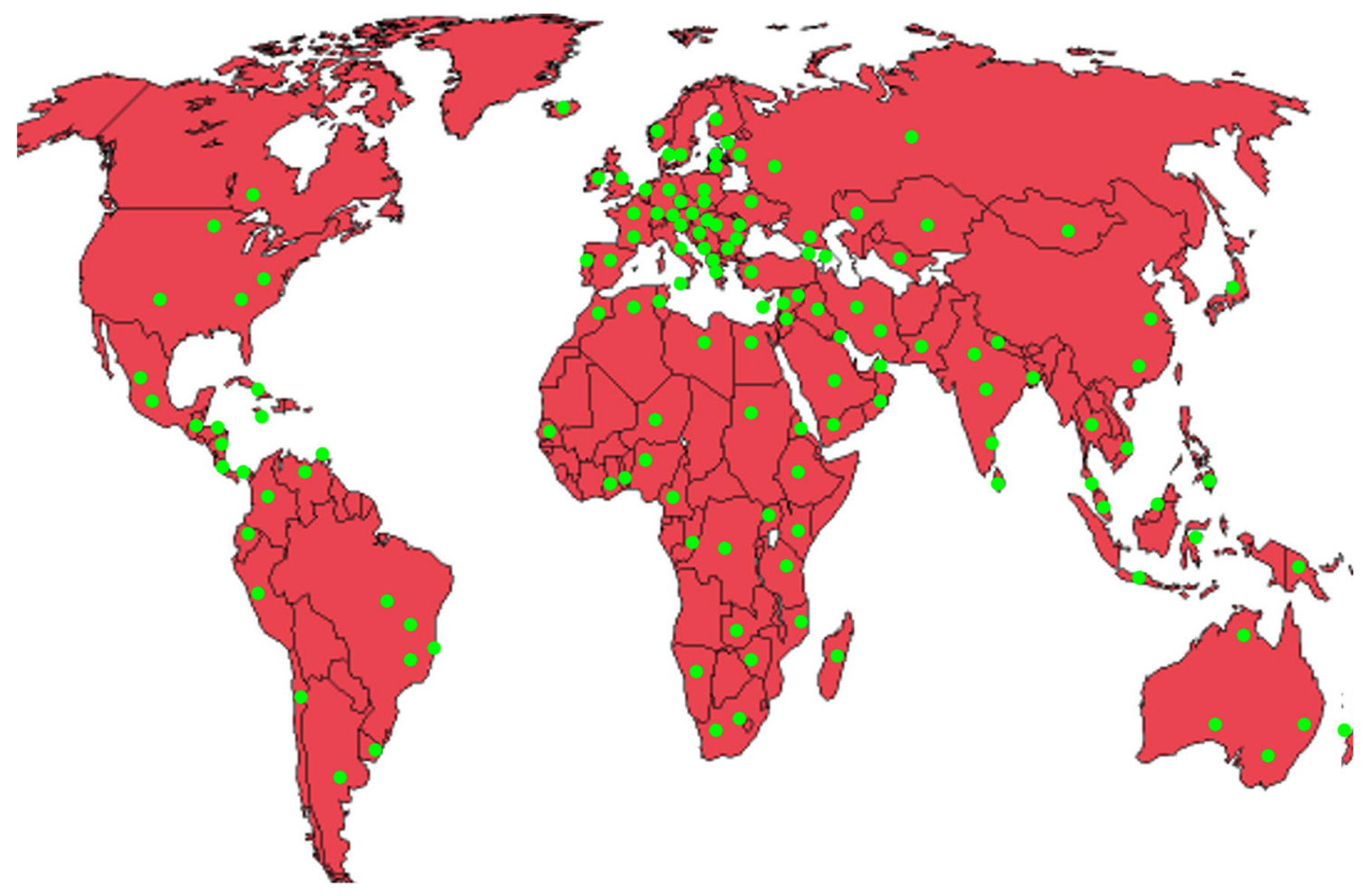

Fig. 1 World-wide dissemination of the pioneering e-Learning materials in Medical Physics (EMERALD, EMIT and EMITEL) (as at June 2020)

under-performance, increased difficulties to balance work and family duties, lack of social contact, and lack of face-to-face engagement with the teacher. [10-12].

Other sources warn that e-Learning may widen the educational access gap [13,14], although this would refer primarily to for-profit-education.

It is also worth noting here that e-Learning poses challenges to keeping data about all participants secure, as a lot of sensitive information would be readily available in one place [15].

While most of the above would be mitigated by the commitment and high motivation of students in higher education and the careful choice of e-Learning providers, there are two factors that cannot and should not be ignored. These in our opinion are some of the most important prerequisites for the introduction of e-Learning.
Fig. 2 The Leonardo da Vinci Award for the EMIT Consortium

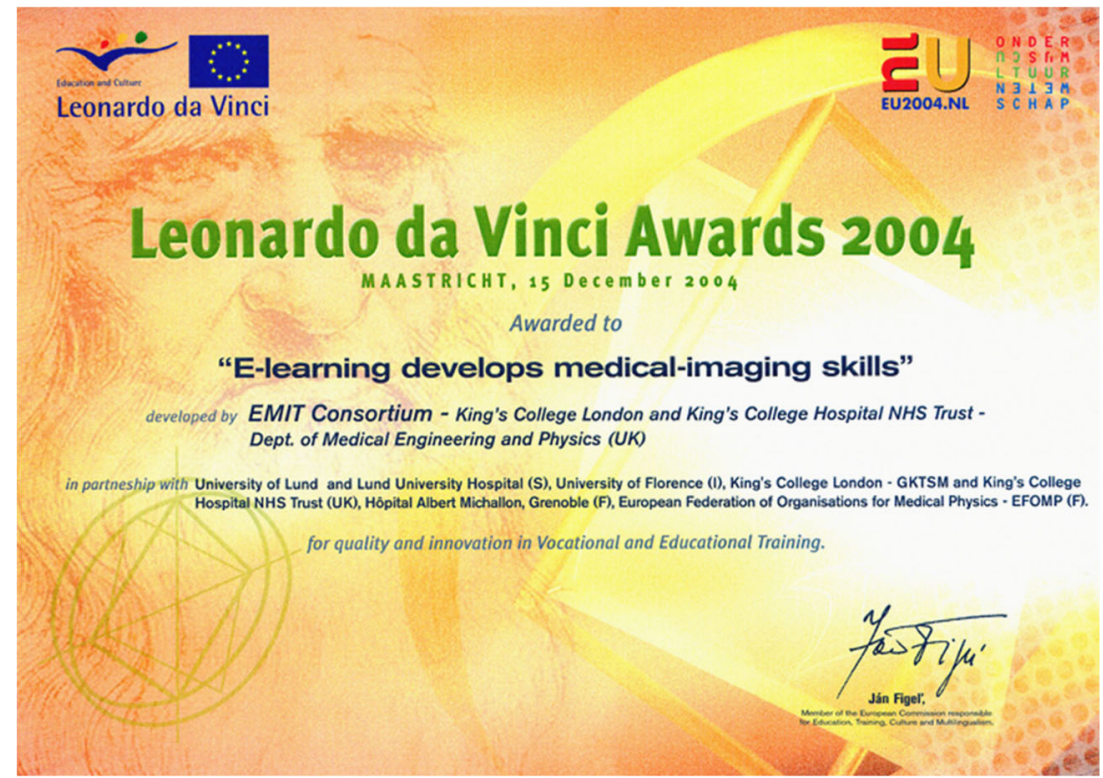


The first one is teacher preparation. As is often underlined $[7,11]$, the assumption that if one can teach in the classroom, this skill is easily transferrable to online courses, is wrong. Every step starting from organising the syllabus, and the following presentation and assessment, has to conform to the eLearning platform features and constraints in terms of space, visual stimulation and timing.

The second is assessing the realistic possibilities for distribution of the already created material. This includes the availability of stable, steady, speedy Internet with enough broadband, and the availability of hardware. If any of these is an issue (as is often the case in Low and Middle Income countries)- an alternative should be sought for the dissemination of the e-Learning material. The dissemination itself has two sides - one is to secure the material is successfully received by the target audience and the second is that it is correctly 'read' by the learner. In this connection it is worth noting that in 2019 at a debate about e-Learning in Africa, the audience, consisting of practitioners, researchers and policymakers in the field of technology use in education across the continent, expressed the opinion that access to internet is not the first and most important factor for education in Africa [16]. Similarly at an interview for Financial Times, a couple of years earlier Bill Gates stated that investment in broadening access to Internet for the continent should not come before many other pressing needs [17].

\section{E-learning in times of crisis}

For the last twenty years the world has witnessed a flood of epidemics (SARS, H1N1v and related, Ebola and others), which have created a critical situation for education. But even without these extreme challenges the world was already dealing with a learning crisis. The term "Learning poverty" was coined to describe the situation where children were unable to read and understand a simple text by the age of 10 . As discussed in a report of the World Bank "...in poor countries the level of illiteracy is as high as $80 \%$ " [18].

With the spread of the Coronavirus disease (COVID-19), among many disruptions to normal life, according to data collected by the World Bank, 160+ countries have mandated temporary school closures, leaving $\sim 1.6$ billion children and youth out of school. To help mitigate the loss of learning, many countries are opting for remote learning to manage and cope with the crisis. What do recent examples show?

\subsection{SARS China}

When the magnitude of the SARS epidemic became widely acknowledged in 2002, China Educational TV, through its 'Classroom on the Air' program, acted quickly to provide necessary education. It became clear that this would provide short-term substitute for students (and their parents) in need of continuing their education while confined to their home during the outbreak. [19]

\subsection{SARS Hong Kong}

As related in the paper SARS epidemic: Teachers' experiences using ICTS, [20] during the same period the uses of ICT (information and communication technologies) in education in Hong Kong, became much more widespread than in the rest of China, (this being underpinned by more frequent computer use at home, and access to the Internet). But the reaction of teachers was ambivalent - there were individual cases of successful employment of ICTs, while some others found that a reliance on ICT-centric teaching and learning styles left them frustrated, and less convinced of the value of ICTs in the education process than they had been before.

\subsection{Swine flu Mexico}

As a result of swine flu, 7 million Mexican students were forced to stay at home in 2009. Before that it had been acknowledged that the availability of ICTs in schools probably is not enough to bring about systemic change; with the appearance of an important exogeneous factor such as a pandemic disease outbreak the task before new technology seemed to be almost impossible. The solution for the region was found through the Telescundaria program [21].

- During the Ebola crisis 2012-2014 academic activities were suspended in many African countries. A report from Nigeria revealed the country's technological inadequacy, especially in the area of e-learning, a "weak and underdeveloped broadband infrastructure which is likely to constitute a major drawback to the nationwide adoption of online services, such as e-learning, information portals...", [22].

In general the conclusion was drawn that while not denying the potentially transformational impact of ICT use to help meet a wide variety of educational objectives, history has shown that bringing about positive substantial change isn't achieved by simply flooding schools with computers and related ICTs.

The World Bank has issued a very helpful guide for rapid implementation of remote learning for all educational levels primary through to higher education in the current situation to respond to the requirements of the global pandemics [23].

\section{The way forward}

While there is no question that e-Learning has been very useful in times of crisis and will be helpful to solve problems in the future, there are several factors that need to be taken into consideration such as: 
- assessing available technologies and what is possible to be implemented realistically;

- content development, so that the content is relevant and tailored to the requirements of e-Learning.

- teacher preparation. As pointed out in many sources [7, $10]$, teacher preparation and training is key to successful e-Learning programs.

- last but not least good guides how to use e-Learning platforms should be made available.

A comprehensive guide of preparation recommendations about font, organisation of lecture handouts, image preparation (especially useful for image-intensive subjects such as medical physics and other medicine-related disciplines), course formatting (i.e. in a modular form, which is very suitable for many health-related degree courses where the lecturers are also engaged as clinical staff), preparation of audio and video material, dealing with copyright issues, lecture structuring and others can be found in [7].

Planning and preparation are key to the success of the process. Content preparation is decisively a foremost factor, as without the content, there is no point of discussing the container. Then comes the need to transmit the created material. For countries with the necessary infrastructure and bandwidth available, this step is easier and in practice there should be no problem in reaching the target audience. It is always a good measure to make content available through a variety of devices. Ways should be sought to secure that e-Learning materials could run on different operating systems and software applications, including mobile phones, as in some LMI countries they are more readily available than desktop and laptop computers. Of course there will be limitations to use this approach for educational modules which rely heavily on diagrams and images.

There are many LMI countries where online education can be a problem due to problems with internet and low bandwidth. For this the offline remote learning model should be discussed and possibilities for transmission through low bandwidth should be checked. As an additional measure the use of educational radio and educational TV should be considered. If technology allows, books and other materials can be distributed electronically (e.g., via social media or WhatsApp). Teleteaching, while not e-Learning in itself, can be implemented within the e-Learning delivery, however it has to be taken into account that tele-teaching cannot handle courseworks and exams delivery.

Word of caution - videos could offer valuable learning resources, provided there is sufficient bandwidth and also that they have unique contribution to the educational process. Simply recording a teacher delivering a lecture and making it available in most cases is not sufficient and would take up valuable memory space. Simulations are another very effective teaching tool in health related disciplines. However their creation requires a combination of excellent IT skills and good paedagogical approach; it is also very time-consuming. On the other hand a specific problem with simulations is their relatively short life cycle (often less than 5 years). The main reason for this is the upgrade of software platforms, what in most cases has restricted the use of simulations. And this is without the additional complication of transmitting the sophisticated material.

Sustaining a remote learning module through balancing the delivery of content and student engagement is easily achieved by e-Learning platforms (or Virtual Learning Systems) which host assignments (individual and collective). This will make learning engaging and more effective. For an example of how to build an educational module based on the Moodle VLE from scratch see reference [7].

There are an increasing number of platforms which are designed with the aim to conduct unseen written exams remotely in a secure cheat-free way, but this still remains a challenge to be resolved. It is always a good idea to design exam questions in such a way that the answers should not be reached simply by consulting notes or online search.

\section{Conclusion}

We are yet to understand how to cope with the current COVID19 Pandemic. For many it is without doubt that the movement of hundreds of millions of people (and viruses) around the world will continue and we will most likely see many more incidents where normal life will be threatened and disrupted. Students and education systems will be substantially affected by these events. For many educators it will always be clear that nothing can replace a person-to-person educational experience. Realistically the place of e-Learning is to complement traditional teaching and learning activities and the most suitable outcome of this is blended learning. There will always be the example of hyperconnected countries like Singapore, Korea or Estonia, who may be ahead of many educational systems in countries with well- established ICT systems. And on the other end there will always be countries that are almost universally acknowledged to be 'behind' in using technology in education. In my opinion the responsibility of the future educator lies in the ability to envisage and provide tools for the lowest common denominator. He/she has to take into consideration in the first place that every learning material has to be a) transmitted b) "deciphered" to reach the learner. And then - every crisis (no matter whether this is an epidemic or else) results in limited resources and every action during a crisis competes for these resources. There is no doubt that actions will be prioritised - life saving actions direct and indirect (health and economy) will come first in times of crisis and we have to be realistic about education. e-Learning cannot be a panacea unless we take into account all other circumstances.

The ways to distribute e-Learning other than internet especially for less well connected countries have to be investigated with sensitivity, goodwill and understanding. To use the 
analogy with the current advice for tackling the COVID-19 pandemic - washing your hands frequently means that you need to have 1) running water and 2) soap. It will be useful to consider alternative modes of communication such as radio, TV or CDs for distribution. Additionally we have to consider the effect of software updates; the lack of practicality of simulations as discussed above and many other limiting factors.

It pays to be prepared - in the case of the MSc programme in Medical Engineering and Physics at King's College London, which has been a pilot e-Learning programme on Moodle VLE since 2011, transfer to the all-online education in 2020 became seamless. A slightly different scenario was employed in the Master's programme of Advanced Studies in Medical Physics at ICTP, Trieste - the excellently prepared content already existed for traditional face-to-face education and the experience from other similar programmes ensured that it went on-line without problems within a month when circumstances required this in 2020. In yet another recent example distance learning education of 6 to 19 year-olds was quickly ensured in an entire country through the purpose-built platform shkolo.bg developed by young IT professionals in Bulgaria. There are many more examples where virtual learning platforms have been implemented successfully at important times.

And yet, when the right time comes, educators have to be prepared to revert to the personal provision of face-to-face education and use e-Learning to complement and enhance it where applicable, adding value to teaching and learning quality.

\section{Compliance with ethical standards}

Conflicts of interest The author declares that she has no conflicts of interest.

Ethics approval The study is a review paper and as such does not include Research involving human participants and/or animals.

Consent to participate There was no involvement of human participants and no need to obtain informed consent.

Conflict of interest The authors declare that they have no competing of interests.

\section{References}

1. The History of eLearning (infographic), EdTechTimes staff, Dec 17, 2012; https://edtechtimes.com/2012/12/17/the-history-ofelearning-infographic/. Accessed 21 July 2020.

2. Morri, A "A bright future for distance learning: one touch/high Alliance promotes interactive 'e-learning' service", Connected Planet, Nov 1997.

3. Masters K, Ellaway R. E-learning in medical education guide 32 part 1: part 1: learning, teaching and assessment. Medical Teacher. 2008;30:455-73.
4. Barr RB, Tagg J. From teaching to learning-a new paradigm for undergraduate education. Change. 1995;27:12-26.

5. Alexander S. E-learning developments and experiences. Educ Train. 2001;43:240-8.

6. Stephenson J, editor. Teaching and learning online pedagogies for new technologies. London: Kogan Page; 2001.

7. Tabakova, V. E-learning in medical physics and engineering: building educational modules with Moodle, CRC Press, 2020, ISBN-13: 978-1138347328.

8. Tabakov, $\mathrm{S}$ et al. The pioneering of e-learning in medical physics, London, 2015, ISBN-13: 978-0955210839.

9. Tabakov S. Global number of medical physicists and its growth 1965-2015. Journal Medical Physics International. 2016;4:78-81.

10. Twinomugisha, A. The promise and challenges of virtual schools, Oct4, 2019. https://blogs.worldbank.org/edutech/promise-andchallenges-virtual-schools. Accessed 21 July 2020.

11. Morrison, S. Online learners' mental health:does anyone care?. Nov 2019. https://news.elearninginside.com/online-learnersmental-health-does-anyone-care. Accessed 21 July 2020.

12. Leonard, W. So Why did MOOCs fail to live up to the hype? Feb 2019. https://www.universityworldnews.com/post.php?story= 20190207110446568 Accessed 21 July 2020.

13. Etherington, C. New study finds eLearning has widened educational access gap. Jan 2019. https://news.elearninginside.com/newstudy-finds-elearning-has-widened-educational-access-gap/; Accessed 21 July 2020

14. Protopsaltis, S, Baum, S. Does Online Education live up to its promise? https://mason.gmu.edu/ sprotops/OnlineEd.pdf Accessed 21 July 2020.

15. Etherington, C. How Florida Virtual School's Controversy has been kept mostly under wraps. Jan 2019. https://news.elearninginside. com/how-florida-virtual-schools-controversy-has-been-keptmostly-under-wraps/ Accessed 21 July 2020.

16. The eLearning Africa 2019 Report. https://www.elearning-africa. com/index.php. Accessed 21 July 2020.

17. An exclusive interview with Bill Gates, Nov1, 2013, Financial Times, FT magazine Life \&Arts. https://www.ft.com/content/ dacd1f84-41bf-11e3-b064-00144feabdc0. Accessed 21 July 2020.

18. Learning Poverty. World Bank Brief, Oct15, 2019. (https://www. worldbank.org/en/topic/education/brief/learning-poverty). Accessed 21 July 2020.

19. Trucano, M. Education and Technology in an age of pandemics, May1, 2009. (https://blogs.worldbank.org/edutech/education-inan-age-of-pandemics. Accessed 21 July 2020.

20. Fox, R. 2004. SARS epidemic: Teachers' experience using ICTs. https://www.ascilite.org/conferences/perth04/procs/pdf/fox.pdf. Accessed 21 July 2020.

21. Calderoni, Jose.1998. Telesecundaria : using TV to bring education to rural Mexico (English). Education and technology technical notes series ; Vol. 3, no. 2 Washington, D.C. : World Bank Group http://documents.worldbank.org/curated/en/ 559251468774647437/Telesecundaria-using-TV-to-bringeducation-to-rural-Mexico Accessed 21 July 2020.

22. Uzor, B. Ebola: Holiday extensions expose Nigeria's e-Learning shortcomings. Sep4 2014, Business Day, Nigeria. https:// businessday.ng/science/article/ebola-holiday-extensions-exposenigerias-e-learning-shortcomings. Accessed 21 July 2020.

23. The World Bank Education Global Practice Guidance Note: Remote learning \& COVID-19 (updated April 7, 2020) https:// data2.unhcr.org/en/documents/details/75420). Accessed 21 July 2020.

Publisher's note Springer Nature remains neutral with regard to jurisdictional claims in published maps and institutional affiliations. 